Original Article

\title{
Faktor-Faktor yang Berhubungan dengan Kesiapsiagaan Masyarakat dalam Menghadapi Bencana Banjir Di Kelurahan Kebon Pala Jakarta Timur
}

\section{Factors That are Related to The Community Preparation in Facing Flood Disasters in Kelurahan Kebon Pala Jakarta Timur}

\author{
Revy Putri Nastiti*, Rafiah Maharani Pulungan, Acim Heri Iswanto \\ Program Studi Kesehatan Masyarakat, Universitas Pembangunan Nasional Veteran Jakarta \\ (*revyputeri98@gmail.com)
}

\begin{abstract}
ABSTRAK
Tujuan penelitian ini adalah untuk mengetahui faktor-faktor yang berhubungan dengan kesiapsiagaan masyarakat menghadapi bencana banjir di Kelurahan Kebon Pala Jakarta Timur. Penelitian ini menggunakan desain cross sectional study, teknik pengambilan data secara purposive sampling dengan besar sampel 84 responden. Instrument penelitian yang digunakan adalah kuesioner. Hasil penelitian ini menunjukkan bahwa 66,7\% masyarakat tidak siap menghadapi bencana banjir di wilayah Kelurahan Kebon Pala Jakarta Timur tahun 2020. Berdasarkan analisis statistik chi square, terdapat faktor yang berhubungan terhadap kesiapsiagaan masyarakat menghadapi bencana banjir, yaitu variabel persepsi terhadap risiko bencana banjir dengan $\mathrm{p}$ value 0,021 ; variabel jenis kelamin dengan $p$ value 0,002 , dan variabel pendidikan dengan $p$ value 0,001 . Peneliti menyarankan agar masyarakat menerapkan perilaku kesiapsiagaan menghadapi bencana banjir sesuai dengan anjuran BNPB.
\end{abstract}

Kata kunci: Banjir, Kesiapsiagaan, Kelurahan Kebon Pala, Masyarakat

\section{ABSTRACT}

The purpose of this study was to determine the factors associated with community preparedness for flooding in Kebon Pala Village, East Jakarta. This study used a cross sectional study design; the data collection technique was purposive sampling with a sample of 84 respondents. This study instrument used was a questionnaire. The results of this study indicate that $66.7 \%$ of people are not ready to face flood disasters in the East Jakarta Kebon Pala District in 2020. Based on chi square statistical analysis, there are factors that related to community preparedness in facing flood disasters, that are the variable perception of flood disaster risk by $p$ value 0.021; gender variable with $p$ value 0,002, and education variable with $p$ value 0,001. Researcher suggests that the community implement the preparedness behavior in facing floods in accordance with BNPB's recommendations.

Key words: Flood, Preparedness, Kebon Pala Village, Community

https://doi.org/10.33860/jik.v15i1.219

(C) 2021 by the authors. Submitted for possible open access publication under the terms and conditions of the Creative

Commons Attribution (CC BY SA) license (https://creativecommons.org/licenses/by-sa/4.0/). 


\section{PENDAHULUAN}

Beberapa wilayah di dunia pernah mengalami bencana. Baik bencana karena faktor alam ataupun faktor non alam. Kejadian bencana dalam tiga dekade terakhir telah meningkat dan menjadi fenomena global ${ }^{1}$. Bencana merupakan rentetan kejadian yang dapat mengganggu aktivitas manusia yang disebabkan oleh ulah manusia ataupun faktor alam itu sendiri, sehingga berakibat hilangnya jiwa manusia maupun harta benda ${ }^{2}$.

International Federation of Red Cross and Red Crescent Societies ${ }^{3}$ melaporkan bahwa dalam rentang waktu tahun 2008 sampai dengan tahun 2017 sebanyak 40,5\%, banjir adalah bencana yang sering melanda beberapa negara di dunia ${ }^{3}$. BNPB melaporkan, sejak tahun 2011 sampai tahun 2020 tanah longsor dan banjir adalah trend bencana yang melanda Indonesia ${ }^{4}$. Berdasarkan data Portal Statistik Sektoral Provinsi DKI Jakarta, curah hujan ekstrim turun sejak 31 Desember 2019 sampai dengan 1 Januari $2020^{5}$. Tinggi nya curah hujan tersebut membuat sebanyak 60\% atau 157 Kelurahan di Jakarta terendam banjir. Wilayah Jakarta Timur merupakan daerah terparah yang dilanda banjir, yaitu sekitar $77 \%{ }^{5}$.

Kelurahan Kebon Pala adalah salah satu wilayah di daerah Jakarta Timur yang juga terdampak banjir cukup serius. Berdasarkan studi pendahuluan yang dilakukan oleh peneliti pada bulan Februari tahun 2020, sejumlah lokasi di Kelurahan Kebon Pala yaitu, RW (rukun warga) 1, 4, 6, 9, 10, dan 11 adalah RW yang terdampak banjir. Menurut Kepala Seksi Kesejahteraan Rakyat, puncak banjir terbesar adalah yang terjadi menjelang pergantian tahun 2019 ke tahun 2020. Ketinggian banjir dapat mencapai $150 \mathrm{~cm}$.

Untuk mampu menghadapi ancaman bencana, seseorang harus memiliki kesiapsiagaan. Kesiapsiagaan merupakan satu kesatuan aksi yang dilaksanakan selaku usaha preventif menghadapi bencana melalui prosedur secara efektif dan efisien ${ }^{6}$.

Penelitian ini bertujuan untuk mengetahui faktor-faktor yang berhubungan dengan kesiapsiagaan masyarakat dalam menghadapi bencana banjir di Kelurahan Kebon Pala, Jakarta Timur. Penelitian dilaksanakan karena frekuensi kejadian banjir sangat sering dialami di daerah tersebut.

\section{METODE PENELITIAN}

Penelitian ini menggunakan rancangan survei cross sectional. Penelitiaan ini dilaksanakan sejak bulan Februari hingga Juni tahun 2020. Populasi penelitian adalah seluruh masyarakat Kelurahan Kebon Pala. Dalam penelitian ini menggunakan purposive sampling, dimana jumlah sampel sebanyak 84 orang. Data yang digunakan adalah data primer dan sekunder. Data primer diperoleh dari wawancara langsung responden menggunakan kuesioner melalui google form. Sedangkan data sekunder dari Kelurahan Kebon Pala.

Teknik analisis data menggunakan univariat dan bivariat. Analisis bivariat menggunakan chi square dengan membandingkan nilai $\mathrm{p}$ dengan nilai alpha $(0,05)$. Apabila nilai $\mathrm{p}<$ nilai alpha, maka hubungan antara kedua variabel akan terbentuk. Namun, dikatakan tidak ada hubungan antara kedua variabel jika nilai $\mathrm{p}$ lebih besar dari nilai alpha.

\section{HASIL}

Tabel 1 menunjukkan bahwa responden yang siap menghadapi bencana banjir yaitu sebanyak 28 responden atau 33,3\% dari 84 responden di wilayah Kelurahan Kebon Pala Jakarta Timur. Tabel 2 menunjukkan bahwa faktor predisposisi yang paling berpengaruh terhadap kesiapsiagaan masyarakat menghadapi bencana banjir ialah kurang baik nya persepsi terhadap risiko banjir yaitu sebanyak 60 responden atau $71,4 \%$.

\begin{tabular}{|c|c|c|}
\hline $\begin{array}{c}\text { Kesiapsiagaan } \\
\text { Masyarakat }\end{array}$ & $\begin{array}{c}\text { Jumlah } \\
(n=84)\end{array}$ & $\%$ \\
\hline $\begin{array}{l}\text { Siap menghadapi } \\
\text { bencana banjir }\end{array}$ & 28 & 33,3 \\
\hline $\begin{array}{l}\text { Tidak siap } \\
\text { menghadapi } \\
\text { bencana banjir }\end{array}$ & 56 & 66,7 \\
\hline
\end{tabular}

Tabel 3 menunjukkan bahwa distribusi responden didominasi oleh Pria sebanyak 51 responden dengan persentase $60,7 \%$ dari 84 responden yang diwawancarai di wilayah Kelurahan Kebon Pala Jakarta Timur. Distribusi umur responden terlihat bahwa umur $\geq 34$ tahun lebih banyak dibandingkan umur < 34 tahun yaitu sebanyak 43 responden dengan persentase $51,2 \%$ dari 84 responden yang diwawancarai di wilayah Kelurahan Kebon Pala Jakarta Timur dengan median data umur adalah 34. 
Tabel 2. Distribusi Frekuensi Faktor

Predisposisi Kesiapsiagaan Masyarakat Menghadapi Bencana Banjir

\begin{tabular}{lcc}
\hline \multicolumn{1}{c}{ Variabel } & $\begin{array}{c}\text { Jumlah } \\
(\mathbf{n = 8 4})\end{array}$ & $\%$ \\
\hline \multicolumn{4}{l}{ Pengalaman mengalami bencana } & banjir \\
Pernah & 58 & 69,0 \\
Tidak pernah & 26 & 31,0 \\
Persepsi terhadap risiko banjir & \\
Baik & 24 & 28,6 \\
Kurang & 60 & 71,4 \\
\hline
\end{tabular}

Tabel 3. Distribusi Frekuensi Faktor Karakteristik Responden terhadap Kesiapsiagaan Masyarakat Menghadapi Bencana Banjir

\begin{tabular}{lcc}
\hline \multicolumn{1}{c}{ Variabel } & $\begin{array}{c}\text { Jumlah } \\
(\mathbf{n = 8 4})\end{array}$ & $\mathbf{\%}$ \\
\hline Jenis kelamin & & \\
$\begin{array}{l}\text { Wanita } \\
\text { Pria }\end{array}$ & 33 & 39,3 \\
Umur & 51 & 60,7 \\
$<34$ tahun & 41 & 48,8 \\
$\geq 34$ tahun & 43 & 51,2 \\
$\begin{array}{l}\text { Pekerjaan } \\
\text { Bekerja }\end{array}$ & & \\
Tidak bekerja & 55 & 65,5 \\
Pendidikan & 29 & 34,5 \\
Tinggi & & \\
Rendah & 35 & 41,7 \\
\hline
\end{tabular}

Sebanyak $69 \%$ atau 58 responden mendominasi pernah mengalami kejadian banjir. Hasil menunjukkan bahwa variabel ini memiliki nilai $\mathrm{p}$ sebesar 0,677 dengan OR sebesar 0,7 (95\% CI: 0,3-1,9). Hal ini berarti bahwa tidak ada hubungan statistik antara variabel pengalaman mengalami bencana banjir dengan kesiapsiagaan masyarakatmneghadapi bencana banjir karena nilai $\mathrm{p}>0,05$ (Tabel 4). Tabel 4 menunjukkan bahwa sebesar 58,3\% responden memiliki persepsi yang kurang terhadap risiko banjir. Data menunjukkan variabel ini memiliki $p$ value sebesar 0,021 dengan OR sebesar 3,5 (95\% CI: 1,3-9,6). Hal ini menunjukkan persepsi terhadap risiko banjir memiliki hubungan statistik dengan variabel kesiapsiagaan masyarakat menghdapi bnecana banjir karena nilai $\mathrm{p}<0,05$.
Tabel 5 menunjukkan bahwa responden di dominasi oleh pria yakni berjumlah 51 orang (60,7 \% dari total responden). Hasil uji statistik menunjukkan bahwa nilai kemaknaan variabel jenis kelamin adalah 0,002 dengan OR sebesar 4,9 (95\% CI: 1,9-13,0). Hal ini menunjukkan bahwa jenis kelamin memiliki hubungan statistik dengan kesiapsiagaan masyarakat menghadapi bencana banjir karena nilai $\mathrm{p}<$ 0,05 . Umur dikelompokkan dalam 2 kategori, yaitu diatas nilai mean umur semua responden dan dibawah mean umur semua responden. Tabel 5 menunjukkan bahwa umur diatas median yaitu diatas 34 tahun lebih mendominasi sebagian umur responden yakni sejumlah 43 orang atau $51,2 \%$ dari 84 responden. Hasil uji statistik menunjukkan umur memiliki nilai p sebesar 0,589 dengan OR sebesar 0,7 (95\% CI: 0,3-1,7). Hal ini berarti umur tidak memiliki hubungan statistik dengan kesiapsiagaan masyarakat menghadapi bencana banjir karena nilai $\mathrm{p}>0,05$.

Pekerjaan dibagi dalam 2 kategori. Kategori bekerja, yaitu bekerja sebagai TNI/POLRI, guru, wiraswasta, dan pekerjaan selain yang disebutkan. Sedangkan kategori tidak bekerja adalah ibu rumah tangga, orang tidak bekerja serta orang yang sedang menunggu panggilan lamaan kerja, dan pelajar. Sebanyak $65,5 \%$ atau 55 orang responden mendominasi kategori bekerja. Hasil statistik menunjukkan variabel pekerjaan memiliki $p$ value sebesar 0,168 dengan OR 0,5 (95\% CI: $0,2-1,2)$. Hal ini berarti bahwa variabel pekerjaan tidak memiliki hubungan statistik dengan variabel kesiapsiagaan masyarakat menghadapi bencana banjir karena $\mathrm{p}>0,05$.

Tingkat Pendidikan dibagi menjadi 2 kategori yaitu kategori tinggi untuk lulusan S1 dan SMA, sedangkan rendah untuk lulusan SMP dan SD. Sebanyak 58,3\% atau 49 responden mendominasi kategori tingkat Pendidikan rendah dari total 84 responden. Hasil uji menunjukkan tingkat Pendidikan memiliki $p$ value sebesar 0,000 dengan OR sebesar 6,8 (95\% CI: 2,5-18,8). Hal ini berarti bahwa tingkat Pendidikan memiliki hubungan statistik dengan kesiapsiagaan masyarakat dalam menghadapi bencana banjir karena $\mathrm{p}<0,05$. 
Tabel 4. Analisis Hubungan Faktor Predisposisi terhadap Kesiapsiagaan Masyarakat Menghadapi Bencana Banjir

\begin{tabular}{|c|c|c|c|c|c|c|c|c|c|}
\hline \multirow{3}{*}{ Variabel } & \multicolumn{4}{|c|}{$\begin{array}{c}\text { Kesiapsiagaan menghadapi } \\
\text { bencana banjir }\end{array}$} & \multirow{2}{*}{\multicolumn{2}{|c|}{ Total }} & \multirow{3}{*}{ OR } & \multirow{3}{*}{$\begin{array}{c}(95 \% \\
\text { CI })\end{array}$} & \multirow{3}{*}{ P Value } \\
\hline & \multicolumn{2}{|c|}{ Siap } & \multicolumn{2}{|c|}{ Tidak siap } & & & & & \\
\hline & $\mathbf{n}$ & $\%$ & $\mathbf{n}$ & $\%$ & $\mathbf{n}$ & $\%$ & & & \\
\hline \multicolumn{10}{|c|}{ Pengalaman mengalami bencana banjir } \\
\hline Pernah & 18 & 31,0 & 40 & 69,0 & 58 & 100,0 & \multirow{2}{*}{0,7} & \multirow{2}{*}{$0,3-1,9$} & \multirow{2}{*}{0,677} \\
\hline Tidak pernah & 10 & 38,5 & 16 & 61,5 & 26 & 100,0 & & & \\
\hline \multicolumn{10}{|c|}{ Persepsi terhadap risiko banjir } \\
\hline Baik & 13 & 54,2 & 11 & 45,8 & 24 & 100,0 & \multirow{2}{*}{3,5} & \multirow{2}{*}{$1,3-9,6$} & \multirow{2}{*}{0,021} \\
\hline Kurang & 15 & 25,0 & 45 & 75,0 & 60 & 100,0 & & & \\
\hline
\end{tabular}

Tabel 5. Analisis Hubungan faktor karakteristik responden terhadap kesiapsiagaan masyarakat menghadapi bencana banjir

\begin{tabular}{|c|c|c|c|c|c|c|c|c|c|}
\hline \multirow{3}{*}{ Variabel } & \multicolumn{4}{|c|}{ Kesiapsiagaan menghadapi bencana banjir } & \multirow{2}{*}{\multicolumn{2}{|c|}{ Total }} & \multirow{3}{*}{ OR } & \multirow{3}{*}{$\begin{array}{c}(95 \%) \\
\text { CI })\end{array}$} & \multirow{3}{*}{ P Value } \\
\hline & \multicolumn{2}{|c|}{ Siap } & \multicolumn{2}{|c|}{ Tidak siap } & & & & & \\
\hline & $\mathbf{n}$ & $\%$ & $\mathbf{n}$ & $\%$ & $\mathbf{n}$ & $\%$ & & & \\
\hline Jenis kelamin & & & & & & & & & \\
\hline Wanita & 18 & 54,5 & 15 & 45,5 & 33 & 100,0 & 4,9 & $1,9-$ & 0,002 \\
\hline Pria & 10 & 19,6 & 41 & 80,4 & 51 & 100,0 & & 13,0 & \\
\hline Umur & & & & & & & & & \\
\hline$<34$ tahun & 12 & 29,3 & 29 & 70,7 & 41 & 100,0 & 0,7 & $0,3-$ & 0,589 \\
\hline $\begin{array}{l}\geq 34 \text { tahun } \\
\text { Pekeriaan }\end{array}$ & 16 & 37,2 & 27 & 62,8 & 43 & 100,0 & & 1,7 & \\
\hline Bekerja & 15 & 27,3 & 40 & 72,7 & 55 & 100,0 & 0,5 & $0,2-$ & 0,168 \\
\hline Tidak bekerja & 13 & 44,8 & 16 & 55,2 & 29 & 100,0 & & 1,2 & \\
\hline Pendidikan & & & & & & & & & \\
\hline Tinggi & 20 & 57,1 & 15 & 42,9 & 35 & 100,0 & 6,8 & $2,5-$ & 0,001 \\
\hline Rendah & 8 & 16,3 & 41 & 83,7 & 49 & 100,0 & & 18,8 & \\
\hline
\end{tabular}

\section{PEMBAHASAN}

Hubungan Pengalaman Mengalami Banjir dengan Kesiapsiagaan Masyarakat Menghadapi Bencana Banjir

Hasil uji chi square didapatkan $p$ value sebesar 0,677 dengan OR sebesar 0,7 (95\% CI: 0,3-1,9). Hal ini berarti bahwa tidak ada hubungan antara pengalaman mengalami bencana banjir dengan kesiapsiagaan masyarakat menghadapi bencana banjir. Penelitian ini sejalan dengan penelitian yang dilakukan oleh Septiana (2019) ${ }^{7}$ pada perawat puskesmas di Kabupaten Bandung ${ }^{7}$. Penelitian tersebut mengatakan bahwa tidak ada korelasi antara pengalaman bencana sebelumnya dengan kesiapsiagaan perawat dalam menghadapi bencana banjir dengan $p$ value 0,256 . Namun, sebaliknya penelitian ini tidak sejalan dengan Onwuemele A $(2018)^{8}$ yang melakukan penelitian di Lagos Megacity, Nigeria. Onwuemele mengatakan bahwa seseorang yang mempunyai pengalaman mengalami banjir di masa lalu, maka akan lebih peduli terhadap risiko banjir yang mungkin terjadi dibanding dengan responden yang belum pernah mengalami bencana banjir di masa lalu ${ }^{8}$. Novita (2015) juga menyatakan hal yang sama yaitu, ada hubungan antara pengalaman sebelumnya dengan kesiapsiagaan masyarakat menghadapi bencana banjir dengan $p$ value 0,0149 .

Menurut Jean Piaget dalam ${ }^{10}$ seseorang yang telah melewati banyak persoalan dalam kehidupannya, akan dapat semakin mengembangkan pemikiran dan pengetahuannya ${ }^{10}$. Sedangkan, Darmawan ${ }^{11}$ mengatakan pandangaan individu terhadap lingkungan sekitarnya akan menghasilkan sebuah pengalaman. Pengalaman tersebut selanjutnya dapat menjadi acuan seorang individu dalam melakukan kegiatan atau aktivitas di kemudian hari. Pengalaman seperti buku referensi yang dijadikan landasan atas pengambilan keputusan invidu dalam kehidupannya ${ }^{11}$.

Dalam penelitian ini pengalaman mengalami banjir tidak berhubungan dengan kesiapsiagaan masyarakat dalam menghadapi bencana banjir mungkin dikarenakan 
masyarakat menganggap banjir bukanlah suatu ancaman yang membahayakan. Mereka cenderung menganggap banjir merupakan bencana biasa yang sering melanda Kelurahan Kebon Pala setiap tahun nya. Hal ini juga di perkuat karena tidak ada korban jiwa yang diakibatkan oleh banjir di Kelurahan Kebon Pala. Akibat dari banjir di Kelurahan Kebon Pala adalah hilangnya harta benda dan berkasberkas penting milik kelurahan. Hal lain yang mengakibatkan pengalaman tidak berhubungan dengan kesiapsiagaan mungkin karena responden tidak mengisi kuesioner yang diajukan dengan seksama. Hal ini mungkin terjadi karena kuesioner di muat dalam laman google form sehingga peneliti tidak dapat memastikan langsung jawaban yang diberikan oleh responden.

\section{Hubungan Persepsi terhadap Risiko Banjir dengan Kesiapsiagaan Masyarakat Menghadapi Bencana Banjir}

Hasil uji bivariat chi square didapatkan $p$ value sebesar 0,021 dengan OR sebesar 3,5 (95\% CI: 1,3-9,6). Hal tersebut berarti bahwa seseorang yang memiliki persepsi risiko kurang baik terhadap banjir akan berpeluang 3,5 kali tidak siap menghadapi bencana banjir dibanding seseorang yang memiliki persepsi risiko baik terhadap banjir. Hal ini sejalan dengan penelitian yang dilakukan oleh Kurnianto ${ }^{12}$ yang dilakukan di pesisir pantai Kecamatan Sumur, Banten pada 174 responden ${ }^{12}$. Penelitian tersebut menyebutkan bahwa 144 responden memiliki persepsi yang baik terhadap bencana dan memiliki tingkat kesiapsiagaan yang baik terhadap bencana.

Penelitian yang sama juga dilakukan oleh $\mathrm{Xu}$ D dkk (2018) ${ }^{13}$ yang menyebutkan gambaran persepsi risiko terhadap bencana longsor di wilayah Waduk Tiga Ngarai di Cina Barat Daya tahun 2018 ${ }^{13}$. Hasil penelitian tersebut membuktikan bahwa masyarakat memiliki kesiapsiagaan bencana yang buruk akibat persepsi risiko yang buruk pula. Penelitian lain juga dilakukan oleh ${ }^{14}$ di 4 distrik di Kota Jingdezhen, China yang menyebutkan bahwa tingkat persepsi masyarakat terhadap banjir di salah satu distrik, yaitu distrik Changjiang ialah tinggi ${ }^{14}$. Tingginya persepsi risiko dapat diartikan bahwa masyarakat memiliki persepsi risiko yang kurang baik terhadap banjir. Penelitian tersebut mengatakan bahwa ada beberapa faktor yang mempengaruhi tinggi nya persepsi risiko ialah, tingkat
Pendidikan yang rendah, kurangnya pengetahuan, serta ketidakpercayaan pada pemerintah. Dengan alasan tersebut dapat dikatakan pula seseorang dengan tingkat persepsi risiko tinggi terhadap banjir maka tingkat kesiapsiagaan terhadap banjir nya menjadi rendah. ${ }^{8}$ dalam penelitian nya juga mengatakan bahwa peningkatan kesiapsiagaan menghadapi bencana banjir diiringi semakin tinggi nya pula persepsi kekhawatiran masyarakat terhadap risiko banjir ${ }^{8}$.

Sugihartono (2007) $)^{15}$ menunjukkan bahwa persepsi adalah kapasitas otak untuk menerjemahkan rangsangan ke dalam indera manusia ${ }^{15}$. Ada berbagai perspektif berbeda pada tiap orang untuk mengartikan sebuah rangsangan. Ada orang yang menafsirkan sesuatu dengan persepsi baik atau positif dan ada pula persepsi negatif yang akan mempengaruhi perilaku manusia secara nyata. Sedangkan, menurut ${ }^{16}$ persepsi adalah proses organisasi menafsirkan rangsangan yang diperoleh oleh organisme atau individu sedemikian rupa sehingga menjadi sesuatu yang signifikan dan merupakan suatu proses dalam diri individu ${ }^{16}$.

Dalam penelitian ini persepsi masyarakat terkait risiko bencana banjir adalah kurang baik. Masyarakat Kelurahan Kebon Pala beranggapan bahwa banjir bukanlah hal yang memiliki risiko berbahaya sehingga mereka acuh tak acuh terhadap datangnya bencana banjir. Banjir hampir setiap tahun melanda kawasan Kelurahan Kebon Pala namun, masyarakat belum juga sadar akan bahaya yang mungkin saja dapat terjadi. Berdasarkan data kuesioner, menyebutkan bahwa responden menganggap membuat perencanaan persiapan bencana banjir merupakan tanggung jawab pemerintah.

\section{Hubungan Jenis Kelamin dengan Kesiapsiagaan Masyarakat Menghadapi Bencana Banjir}

Hasil analisis chi square pada tabel 12 didapatkan $p$ value 0,002 dengan $\mathrm{OR}=4,9(95 \%$ CI: 1,9-13,0) hal ini berarti bahwa pria memiliki peluang 4,9 kali tidak siap menghadapi bencana banjir dibanding wanita. Hal ini sejalan dengan Novita (2015) yang melakukan penelitian di Gampong Garot Aceh Besar dan menyatakan bahwa $62,7 \%$ wanita memiliki kesiapsiagaan yang baik ${ }^{9}$. Glago (2019) ${ }^{17}$ juga melakukan penelitian mengenai kesadaran dan kesiapsiagaan bencana pada tingkat 
penduduk $^{17}$. Penelitian nya menyimpulkan bahwa responden dengan jenis kelamin wanita $(63,6 \%)$ lebih sadar akan risiko banjir di banding dengan responden pria. Penelitian yang dilakukan oleh ${ }^{18}$ sejalan dengan penelitian yang dilakukan oleh ${ }^{19}$ yang mengemukakan bahwa tidak ada hubungan yang signifikan antara gender dengan perilaku kesiapsiagaan bencana $^{1819}$.

Namun, beberapa penelitian menunjukkan bahwa pria memiliki perilaku kesiapsiagaan yang lebih tinggi dibanding dengan wanita ${ }^{20}$. Dalam kasus-kasus ini, wanita mungkin lebih tidak siap daripada pria karena perbedaan peran dan tanggung jawab yang ditentukan secara sosial di antara mereka. Ini juga bisa karena ketidaksetaraan di antara mereka dalam hal kekuatan pengambilan keputusan, partisipasi dalam organisasi kesiapsiagaan darurat dan akses ke sumber daya ${ }^{21}$. Namun demikian, beberapa penelitian telah menunjukkan bahwa perempuan menganggap peristiwa atau ancaman bencana lebih serius dan berisiko daripada laki-laki, dan mereka umumnya lebih banyak terlibat dalam kegiatan mitigasi dan kesiapsiagaan daripada laki-laki, terutama dalam kegiatan yang berpusat di dalam rumah ${ }^{22}$.

Pria dan wanita memandang dunia dengan cara yang berbeda. Begitu juga dengan memahami sebuah risiko yang akan terjadi pada dirinya. Perbedaan ini dapat dikaitkan dengan konteks budaya dan sosial yang dianut masingmasing pribadi ${ }^{23}$. Pria akan lebih mudah mengakses informasi karena pergaulan luas di dunia pekerjaan nya. Namun, wanita terbatas pada pengasuhan anak sehingga kurang dapat berinteraksi dengan lingkungan luar walaupun hanya sebatas dari menonton televisii ${ }^{24}{ }^{25}$ menemukan perempuan lebih khawatir tentang potensi risiko banjir ${ }^{25}$. Beberapa penelitian melaporkan bahwa pria memiliki kepercayaan, perilaku proaktif, dan kesiapsiagaan yang tinggi saat keadaan darurat. Perilaku demikian biasanya didorong oleh peran sosial pria dalam keluarga $^{24}$. Namun, sebaliknya penelitian yang dilakukan di Wujie Taiwan mengemukakan bahwa secara statistik wanita lebih siap dalam hal berpikir tentang kemungkinan bahaya yang akan terjadi di masa depan dibandingkan dengan pria ${ }^{26}$.

Richard dalam Suhardin ${ }^{27}$ mengatakan bahwa wanita memiliki karakteristik alamiah yaitu memiliki kepedulian terhadap lingkungan, perhatian terhadap permasalahan yang ada dalam lingkungan, serta membenahi dan menata lingkungan ${ }^{27}$. Hal ini mungkin membuat wanita lebih siap menghadapi bencana banjir di banding pria. Namun, Tidak ada literatur yang menjelaskan bahwa wanita atau pria memiliki tingkat kecerdasan atau kognitif yang berbeda. Namun pada kenyataannya, wanita lebih waspada, lebih perhatian dan lebih teliti ketika diberi tugas atau melakukan sesuatu, tetapi ini tidak menjelaskan dan membuktikan bahwa wanita memiliki kecerdasan atau tingkat kognitif yang lebih baik dengan sikap seperti itu ${ }^{28}$.

Pada masyarakat Kelurahan Kebon Pala Jakarta Timur diketahui bahwa responden dengan jenis kelamin wanita sebanyak 33 orang $(39,3 \%)$ dan pria sebanyak 51 orang $(60,7 \%)$. Perbedaan jumlah masyarakat berdasarkan jenis kelamin yang didapat berdasarkan keadaan yang ditemui oleh peneliti. Hal ini mungkin terkait kuesioner diajukan dalam bentuk laman google form sehingga lebih banyak pria yang mengakses di banding wanita. Berdasarkan hasil kuesioner juga didapat lebih banyak jumlah pria bekerja di banding wanita bekerja. Seseorang yang bekerja mungkin saja lebih banyak menggunakan gadget sebagai penunjang pekerjaan nya. Sehingga pria lebih mendominasi menjadi responden dalam penelitian ini.

\section{Hubungan Umur dengan Kesiapsiagaan Masyarakat Menghadapi Bencana Banjir}

Hasil analisis chi square didapatkan $p$ value sebesar 0,483 yang artinya tidak ada hubungan antara umur dengan kesiapsiagaan masyarakat menghadapi bencana banjir dengan $\mathrm{OR}=0,6(95 \%$ CI: 0,3-1,6). Hal ini tidak sejalan dengan penelitian Septiana ${ }^{7}$ pada perawat puskesmas di Kabupaten Bandung yang menyebutkan umur mempunyai hubungan dengan kesiapsiagaan ${ }^{7}$. Mubarak ${ }^{29}$ mengatakan umur merupakan faktor yang sangat penting ${ }^{29}$. Semakin betambah umur seseorang maka semakin banyak pula pengalaman yang dimilikinya. Umur juga mempengaruhi daya ingat seseorang. Sehingga semakin bertambah umur makan pengetahuan pula bertambah. Pengetahuan yang dimiliki seseorang akan membaik karena berkembangnya pola pikir seseorang. Semakin tua seseorang, maka semakin bijaksana ${ }^{30}$.

Dalam penelitian ini umur tidak berhubungan dengan kesiapsiagaan bencana banjir mungkin dikarenakan mayoritas tingkat 
pendidikan responden dalam penelitian ini rendah. Carter (2008) mengatakan bahwa tingkat pendidikan akan mempengaruhi kognitif seseorang ${ }^{31}$. Seorang individu dengan tingkat Pendidikan tinggi maka tinggi pula tingkat penalarannya. Hal tersebut mungkin membuat umur tidak memiliki hubungan antara kesiapsiagaan bencana dalam penelitian ini.

\section{Hubungan Pekerjaan dengan Kesiapsiagaan Masyarakat Menghadapi Bencana Banjir}

Hasil analisis chi square didapatkan bahwa $p$ value sebesar 0,168 dengan OR 0,5 (95\% CI: 0,2-1,2). Hal tersebut berarti tidak ada hubungan antara pekerjaan dengan kesiapsiagaan masyarakat menghadapi bencana banjir. Hal ini sejalan dengan penelitian yang di lakukan oleh ${ }^{17}$ yang menyatakan bahwa tidak ada hubungan signifikan antara pekerjaan penduduk dan kesadaran banjir dengan nilai $\mathrm{p}$ value sebesar $0,073^{17}$. Takao K (2004) ${ }^{32}$ juga menyatakan bahwa kesadaran seseorang akan risiko bencana banjir tidak tergantung pada pekerjaan seorang tersebut ${ }^{32}$.

Penelitian yang dilakukan oleh Pangesti $(2012)^{33}$ menjelaskan bahwa pekerjaan seseorang akan berpengaruh pada pengetahuan dan pengalamannya ${ }^{33}$. Menurut ${ }^{34}$, jenis pekerjaan mempengaruhi bentuk dan pola penggunaan internet seseorang ${ }^{34}$. Seseorang yang bekerja dan memiliki kapasitas keuangan yang tinggi mampu membayar semua layanan yang tersedia di internet. Hal ini juga disebabkan oleh fakta bahwa tempat kerja mereka memadai dan banyak fasilitas infrastruktur internet yang diberikan sehingga mereka dapat dengan mudah dan cepat mengakses internet. Seseorang yang bekerja dan memiliki akses informasi maka akan mempengaruhi pengetahuan nya. Seseorang yang memiliki pengetahuan tinggi mengenai banjir maka akan tinggi pula upaya kesiapsiagaan nya menghadapi bencana banjir. Pengetahuan yang tinggi akan diikuti tindakan atau sikap yang sejalan. Sehingga seseorang dengan pengetahuan baik maka sikap nya pula akan baik dan peduli terhadap upaya kesiapsiagaan bencana ${ }^{35}$.

Dalam penelitian ini pekerjaan tidak berhubungan dengan kesiapsiagaan masyarakat dalam menghadapi bencana banjir mungkin dikarenakan oleh mayoritas persepsi risiko terhadap banjir tidak baik. Persepsi seseorang akan mempengaruhi cara bertindak seseorang pula. Sehingga dalam hal ini pekerjaan tidak akan berpengaruh pada kesiapsiagaan dikarenakan faktor persepsi risiko terhadap banjir yang buruk.

\section{Hubungan Pendidikan dengan Kesiapsiagaan Masyarakat Menghadapi Bencana Banjir}

Hasil uji bivariat chi square didapatkan p value sebesar 0,001 dengan OR sebesar 6,8 (95\% CI: 2,5-18,8). Hal ini berarti bahwa seseorang dengan tingkat Pendidikan rendah akan berpeluang 6,8 kali tidak siap menghadapi bencana banjir dibanding dengan seseorang yang memiliki tingkat Pendidikan tinggi. Penelitian ini sejalan dengan penelitian yang dilakukan oleh Maryanti dkk (2017) ${ }^{36}$ di Kelurahan Giritirto, Kecamatan Wonogiri. Hasil penelitian menyebutkan bahwa terdapat hubungan antara tingkat Pendidikan dengan kesiapsiagaan ${ }^{36}$. Penelitian yang sama juga dilakukan oleh Fitriningtriyas (2014) ${ }^{37}$ di Desa Jabung, Kabupaten Klaten. Fitriningtyas mengatakan bahwa masyarakat dengan tingkat Pendidikan akhir SMP dan SD cenderung memiliki indeks kesiapsiagaan yang rendah ${ }^{37}$. Hoffmann (2020) ${ }^{38}$ dalam penelitian nya juga menyimpulkan bahwa tingkat Pendidikan yang berbeda dapat mempengaruhi kerentanan bencana secara langsung dan tidak langsung. Secara langsung, melalui Pendidikan dan pembelajaran, individu memperoleh pengetahuan, kemampuan keterampulan dan persepsi itu memungkinkan mereka untuk secara efektif mempersiapkan dan mengatasi konsekuensi dari bencana ${ }^{38}$. Secara tidak langsung, Pendidikan memberikan individu dan rumah tangga akses ke sumber daya materi, informasi dan sosial, yang dapat membantu mengurangi kerentanan bencana mereka. Tingkat Pendidikan yang lebih baik ditemukan berhubungan positif dengan berbagai hasil kerentanan, seperti tingkat kesiapsiagaan, reaksi untuk peringatan dinni, evakuasi dan keputusan relokasi, adaptasi terhadap perubahan lingkungan kondisi, dan kemampuan untuk mengatasi konsekuensi dari bencana setelahnya ${ }^{38}$.

Menurut Carter (2008) ${ }^{31}$ memiliki taraf pendidikan yang tinggi akan mempengaruhi pengalaman yang dimiliki seseorang, sebab ia akan mudah mencerna berbagai informasi yang diterima. Kognitif pula akan berkembang seiring pengalaman yang dimilikinya. Bukan hanya berpengaruh pada kognitif namun, 
tingginya taraf pendidikan seseorang pula akan berpengaruh pada persepsi dan penalaran seseorang terhadap sesuatu ${ }^{31}$. Dimyanti $(2009)^{39}$ berpendapat bahwa pendidikan dalam ranah kognitif, afektif, dan psikomotor akan meningkatkan kinerja seseorang. Lingkungan kognitif membutuhkan kesadaran, pemahaman, kemampuan menerapkan, menafsirkan, mensintesis, dan mengevaluasi. Area afektif melibatkan pengakuan, keterlibatan, penentuan perilaku, organisasi, dan pembentukan pola kehidupan. Domain psikomotorik adalah kemampuan untuk memahami, mempersiapkan, dan bergerak ${ }^{39}$.

Pada penelitian ini tingkat Pendidikan berhubungan dengan kesiapsiagaan masyarakat menghadapi bencana banjir mungkin dikarenakan dari hasil penelitian jumlah responden yang berpendidikan rendah lebih banyak dibanding dengan yang berpendidikan tinggi. Selain itu persepsi terhadap risiko banjir nya pun tidak baik. Sehingga berakibat pada tidak siapnya masyarakat mneghadapi bencana banjir.

\section{KESIMPULAN DAN SARAN}

Berdasarkanan hasil penelitian,
masyarakat Kelurahan Kebon Pala Jakarta Timur masih tidak siap menghadapi bencana banjir. Tidak ada hubungan bermakna antara pengalaman mengalami bencana banjir, umur, dan pekerjaan dengan kesiapsiagaan masyarakat menghadapi bencana banjir di Kelurahan Kebon Pala Jakarta Timur Tahun 2020. Sedangkan, terdapat hubungan statistik antara persepsi terhadap risiko banjir, jenis kelamin, dan tingkat pendidikan dengan kesiapsiagaan masyarakat terhadap bencana banjir di Kelurahan Kebon Pala Jakarta Timur Tahun 2020.

Saran penelitian ini agar masyarakat melaksanakan upaya kesiapsiagaan menghadapi bencana banjir di tingkat keluarga melalui langkah-langkah siapsiaga bencana banjir sesuai anjuran BNPB agar kedepannya banjir tidak lagi menimbulkan kerugian bagi warga terdampak. Saran bagi Kelurahan Kebon Pala mengadakan simulasi kesiapsiagaan masyarakat menghadapi bencana banjir. Dengan upaya tersebut diharapkan masyarakat menjadi tahu dan mengerti langkah atau respon apa yang seharusnya dilakukan saat terjadi bencana banjir, Memberikan pelatihan kesiapsiagaan menghadapi bencana banjir pada minimal 1 orang dalam sebuah keluarga sehingga dalam sebuah keluarga memiliki anggota keluarga yang siap menghadapi bencana banjir, Menyediakan sistim peringatan dini banjir agar sebelum banjir datang warga dapat bersiap-siap dan menyelamatkan diri serta harta benda yang penting.

\section{DAFTAR PUSTAKA}

1. Amoako C, Boamah EF. The threedimensional causes of flooding in Accra, Ghana. International Journal of Urban Sustainable Development. 2015;7(1):109-29.

2. Indonesia. Undang-Undang Republik Indonesia no 24 tahun 2007 tentang penanggulangan bencana. Jakarta; 2007.

3. International Federation of Red Cross and Red Crescent Societies. World Disasters Report 2018. 2018.

4. BNPB. Data Informasi Bencana Indonesia (DIBI) [Internet]. 2020 [cited 2020 Jul 8]. Available from: http://bnpb.cloud/dibi/tabel3b

5. Portal Statistik Sektoral Provinsi DKI Jakarta. Rekapitulasi Data Banjir DKI Jakarta dan Penanggulangannya Tahun 2002 [Internet]. 2020 [cited 2020 Mar 16]. Available from: http://statistik.jakarta.go.id/rekapitulasi-databanjir-dki-jakarta-dan-penanggulangannyatahun-2020/

6. BNPB. Buku Saku Tanggap Tangkas Tangguh Menghadapi Bencana. Badan Nasional Penanggulangan Bencana. Jakarta; 2017. 62 p.

7. Septiana ME, Fatih H Al. Hubungan Karakteristik Individu demham Kesiapsiagaan Perawat Puskesmas. Jurnal Ilmiah Kesehatan Keperawatan. 2019;15(1):1-6.

8. Onwuemele A. Public perception of flood risks and disaster preparedness in lagos megacity, Nigeria. Academic Journal of Interdisciplinary Studies. 2018;7(3):179-85.

9. Novita D. Faktor-faktor yang Mempengaruhi Kesiapsiagaan Bencana Banjir di Gampong Garot Kecamatan Darul Imarah, Aceh Besar. Skripsi Fakultas Keperawatan. 2015.

10. Suparno P. Teori Perkembangan Kognitif Jean Piaget. Yogyakarta: Kanisius; 2001.

11. Darmawan R. Pengalaman, Usability, dan Antarmuka Grafis: Sebuah Penelusuran Teoritis. ITB Journal of Visual Art and Design. 2013;4(2):95-102.

12. Kurnianto YT. Pengaruh persepsi risiko bencana terhadap kesiapsiagaan bencana pada keluarga di pesisir pantai kecamatan sumur, pandeglang. Skripsi Pogram Studi Psikologi. 2019.

13. Xu D, Peng L, Liu S, Wang X. Influences of Risk Perception and Sense of Place on 
Landslide Disaster Preparedness in Southwestern China. International Journal of Disaster Risk Science. 2018;9(2):167-80.

14. Wang Z, Wang H, Huang J, Kang J, Han D. Analysis of the public flood risk perception in a flood-prone city: The case of Jingdezhen city in China. Water (Switzerland). 2018;10(11).

15. Sugihartono. Psikologi Pendidikan. Yogyakarta: UNY Pers; 2007.

16. Walgito B. Pengantar Psikologi Pendidikan dengan Pendekatan Baru. Bandung: PT. Remaja Rosdakarya; 1990.

17. Glago FJ. Household disaster awareness and preparedness: A case study of flood hazards in Asamankese in the West Akim Municipality of Ghana. Jamba: Journal of Disaster Risk Studies. 2019;11(1):1-11.

18. Najafi M, Ardalan A, Akbarisari A, Noorbala AA, Jabbari H. Demographic determinants of disaster preparedness behaviors amongst Tehran inhabitants, Iran. PLoS Currents. 2015;7(DISASTERS):1-13.

19. Taghizadeh AO, Hosseini M, Navidi I, Mahaki AA, Ammari H, Ardalan A. Knowledge, Attitude and Practice of Tehran's Inhabitants for an Earthquake and Related Determinants. PLoS Currents. 2012;1-16.

20. Austin D. Surviving the next disaster: Assessing the preparedness of communitybased organizations: Boulder; 2010.

21. Citizen Corps. Personal behavior change model for disaster preparedness. Citizen Preparedness Review. 2006;

22. World Health Organization. Gender and health in disasters. 2002;

23. Cutter SL, Tiefenbacher J, Solecki WD. EnGendered Fears: Femininity and Technological Risk Perception. SAGE Journals. 1992;(6):5-22.

24. Cvetković VM, Roder G, Öcal A, Tarolli P, Dragićević $\mathrm{S}$. The role of gender in preparedness and response behaviors towards flood risk in Serbia. International Journal of Environmental Research and Public Health. 2018;15(12).

25. O'Neill E, Brereton F, Shahumyan H, Clinch JP. The Impact of Perceived Flood Exposure on Flood-Risk Perception: The Role of Distance. Risk Analysis an International Journal. 2016;36:2158-86.

26. Roder G, Ruljigaljig T, Lin C-W, Tarolli P. Natural hazards knowledge and risk perception of Wujie indigenous community in Taiwan. Natural Hazards. 2016;81:641-62.

27. Suhardin S. Pengaruh Perbedaan Jenis Kelamin Dan Pengetahuan Tentang Konsep Dasar Ekologi Terhadap Kepedulian Lingkungan. EDUKASI: Jurnal Penelitian Pendidikan Agama dan Keagamaan.
2016;14(1):117-32.

28. Suwaryo PAW, Yuwono P. Faktor-faktor yang mempengaruhi tingkat pengetahuan masyarakat dalam mitigasi bencana alam tanah longsor. Urecol 6th. 2017;305-14.

29. Mubarak. Promosi Kesehatan Sebuah Pengantar Proses Belajar Mengajar dalam Pendidikan. Yogyakarta: Graha Ilmu; 2017.

30. Agus, Budiman. Kuesioner Pengetahuan dan Sikap Dalam Penelitian Kesehatan. Jakarta: Salemba Medika; 2013.

31. Carter WN. A Disaster Manager's Handbook. Asian Development Bank; 2008.

32. Takao K, Motoyoshi T, Sato T, Fukuzondo T, Seo, K. \& Ikeda S. 'Factors determining residents' preparedness for floods in modern megalopolises: The case of the Tokai flood disaster in Japan. Journal of Risk Research. 2004;7(7-8).

33. Pangesti A. Gambaran tingkat pengetahuan dan aplikasi kesiapsiagaan bencana pada mahasiswa Fakultas Ilmu Keperawatan Universitas Indonesia tahun 2012. Jakarta; 2012.

34. Suryani T. Perilaku Konsumen di Era Internet, Implikasi Pada Strategi Pemasaran. Yogyakarta: Graha Ilmu; 2013.

35. LIPI-UNESCO/ISDR. Pengembangan Framework Untuk Mengukur Kesiapsiagaan Masyarakat Terhadap Bencana Alam. Jakarta: LIPI - UNESCO/ISDR; 2006. 512 p.

36. Maryanti S, Lestari E, Putri W, Wardani AR, Haris F. Hubungan Tingkat Pendidikan Masyarakat Terhadap Kesiapsiagaan Bencana Tanah Longsor di Kelurahan Giritirto Kecamatan Wonogiri. Prosiding Seminar Nasional Geografi UMS : ISBN: 978-602361-072-3. 2017;(S 540907024):1-93.

37. Fitriningtiyas K. Hubungan Tingkat Pendidikan Formal Dengan Kesiapsiagaan Dalam Menghadapi Bencana Gempa Bumi Masyarakat Desa Jabung Kecamatan Gantiwarno Kabupaten Klaten. Surakarta; 2014.

38. Hoffmann R, Blecha D. Education and disaster vulnerability in Southeast Asia: Evidence and policy implications. Sustainability (Switzerland). 2020;12(4):117.

39. Dimyanti, Mudjiono. Belajar dan Pembelajaran. Jakarta: Rineka Cipta; 2009. 